\title{
Common agricultural policy and
}

sustainable management of areas with natural handicaps. The Veneto Region case study

\section{Maria Bruna Zolin, Andrea Pastore \& Martina Mazzarolo}

Environment, Development and Sustainability

A Multidisciplinary Approach to the Theory and Practice of Sustainable Development

ISSN 1387-585X

Environ Dev Sustain

DOI 10.1007/s10668-019-00537-8

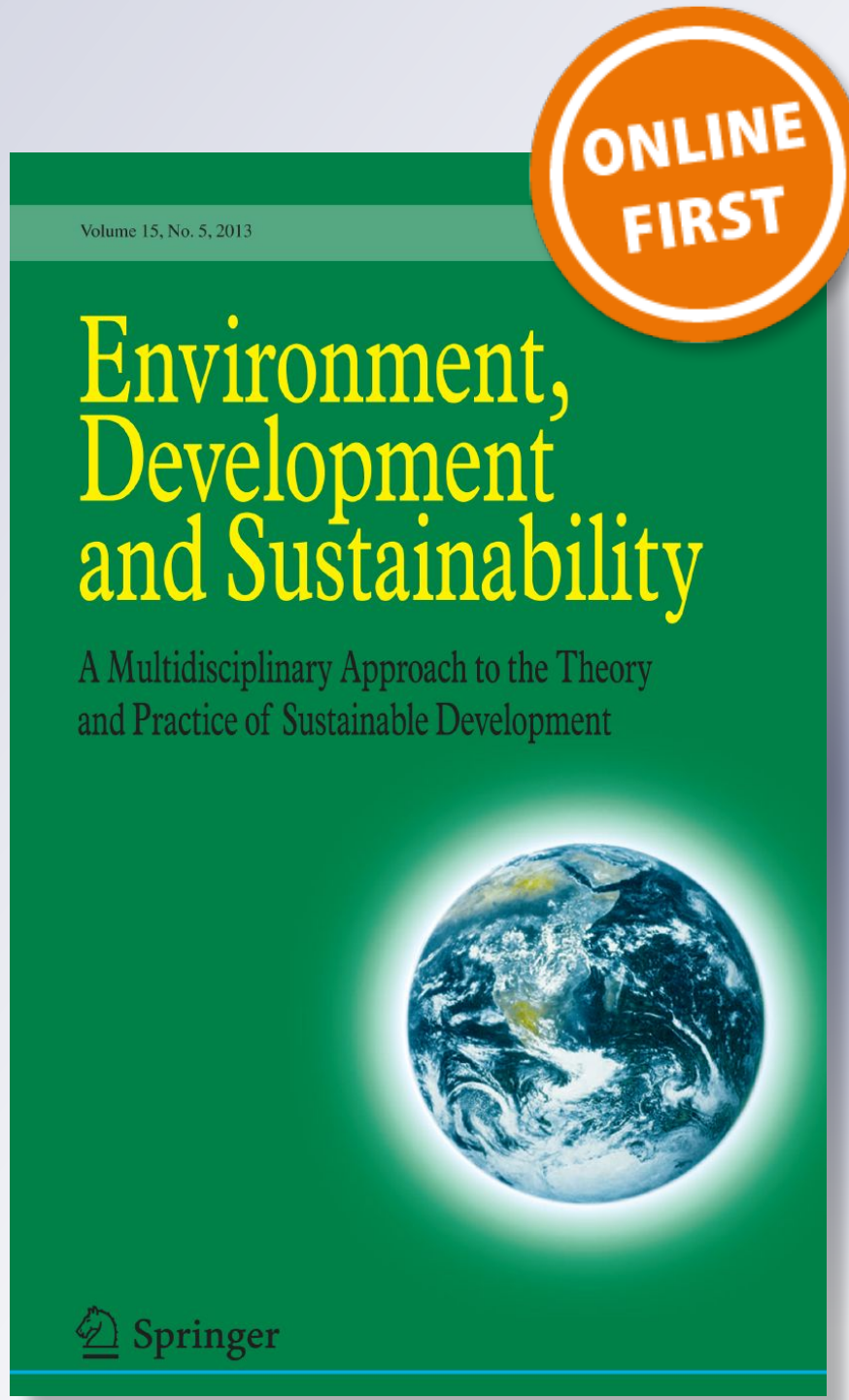

Springer 
Your article is protected by copyright and all rights are held exclusively by Springer Nature B.V.. This e-offprint is for personal use only and shall not be self-archived in electronic repositories. If you wish to self-archive your article, please use the accepted manuscript version for posting on your own website. You may further deposit the accepted manuscript version in any repository, provided it is only made publicly available $\mathbf{1 2}$ months after official publication or later and provided acknowledgement is given to the original source of publication and a link is inserted to the published article on Springer's website. The link must be accompanied by the following text: "The final publication is available at link.springer.com". 


\title{
Common agricultural policy and sustainable management of areas with natural handicaps. The Veneto Region case study
}

\author{
Maria Bruna Zolin ${ }^{1}$ (D) $\cdot$ Andrea Pastore ${ }^{1} \cdot$ Martina Mazzarolo $^{1}$
}

Received: 19 October 2018 / Accepted: 24 November 2019

(c) Springer Nature B.V. 2019

\begin{abstract}
Using a case study based in Veneto Region (Italy), the paper assesses whether the common agricultural policy influences the gross sellable product per hectare of utilised agricultural area, as a proxy of land productivity, and whether this effect changes according to different geographical areas (mountain, hill or plain). The regression analysis shows that the gross sellable product per hectare of utilised agricultural area is negatively correlated with the location of the farm in the mountains, confirming the existence of a gap between mountain and plain farms. The sellable product per hectare of utilised agricultural area is, moreover, positively influenced by the financial support of the first pillar for all farm locations with the exception of hill areas. The European payments of the second pillar, on the other hand, are positively correlated only with the gross sellable product per hectare of utilised agricultural area of hill farms. This trend, far from promoting a balanced and sustainable territorial development, is fuelling a dual agriculture with abandonment of agricultural land, together with environmental degradation and loss of biodiversity in areas with natural handicaps. The Farm Accountancy Data Network of 2015 is the source of microdata.
\end{abstract}

Keywords Public policies · Environmental impact · Regional sustainability · Implementation of public policies

\section{Introduction}

Since 2000, two pillars have characterised the common agricultural policy (CAP). The first pillar (price and market policy) is devoted to supporting farmers' incomes and is focused on environmental sustainability, protection and health and animal welfare. It is oriented

Maria Bruna Zolin

zolin@unive.it

Andrea Pastore

pastore@unive.it

Martina Mazzarolo

martina.mazzarolo@unive.it

1 Department of Economics, Ca' Foscari University Venice, S. Giobbe, 873, 30121 Venice, Italy 
towards achieving food security and safety by providing market measures to balance the impact of external factors (such as bad weather conditions or high price volatility) on vulnerable agricultural markets. The second pillar (rural development policy) meets the specific needs of rural development in each of the EU member states.

The Treaty of Rome (European Economic Community 1957), which provided the objectives to be achieved by the CAP over time (and which have never been modified), at first did not take into account territorial, environmental and socio-economic disparities as its goal. It stated that (paragraph 2 of Article 38), "In working out the common agricultural policy and the special methods for its application, account shall be taken of: (a) the particular nature of agricultural activity, which results from the social structure of agriculture and from structural and natural disparities between the various agricultural regions".

Finally, in 1975, areas with natural handicaps were considered by the Council of the European Economic Community Directive 75/268/EEC on mountain and hill farming and farming in certain less favoured areas. A common factor within areas identified as "less favoured" (LFAs) is that agricultural production or activity is more difficult because of natural handicaps, and this results in severe problems in terms of agricultural land use. These natural handicaps refer, for instance, to negative climatic conditions, altitudes and slopes, or low soil productivity. Areas with natural handicaps generally have a high nature value and a great wealth of biodiversity (McDonald et al. 2000). However, they are discriminated against in terms of income, and not just in relation to the plain areas. They present a scarcely differentiated productive structure and limited job opportunities, as well as reduced access to public utilities and communication services, to mention just a few differentiating factors (Zolin et al. 2017). In these areas, active agriculture plays a decisive role in terms of environmental protection and biodiversity conservation, as well as prevention from extreme climatic events (such as floods). ${ }^{1}$

The main risk linked to natural handicaps is the abandonment of the land, with all the negative consequences associated with such an event, including environmental degradation and loss of biodiversity (McDonald et al. 2000; Agnoletti 2007). Verburg and Overmars (2009) confirmed the same concept using a simulation model; what emerged was that abandonment is concentrated in regions with relatively poor conditions for agricultural use, such as mountain areas. In addition, despite the delayed negative effects of the abandonment of rural areas, this trend could be irreversible (Westhoek et al. 2006).

Furthermore, the implementation of EU legislation (such as EU Regulation no 1305/2013) on support for rural development by the European Agricultural Fund for Rural Development concerning the conservation of natural areas and the rural development policy, together with the prohibition of restoring open spaces currently covered by forests, has resulted in an aggravation of the abandonment issue (Agnoletti 2007). Land abandonment may be due to several factors: environmental (reduction in soil fertility), economic (decrease in raw material prices) and social (depopulation). The environmental impact of abandoning agricultural land can be analysed as an opportunity for ecological restoration or as a threat to biodiversity. Whether the abandonment of the land represents an ecological opportunity or a threat depends on agricultural history and the presence of agro-systems, which, due to their existence, depend on regular management (Haddaway et al. 2013; Defrancesco et al. 2018). Mountain areas generally fall into the latter category.

\footnotetext{
1 According to the recent Council Regulation (EC) 1305/2013, LFAs are "Areas with Natural Constraints" (ANC); this included mountain areas defined as areas handicapped by a short growing season because of the high altitudes and steep slopes at a lower altitude, or because of the combination of the two.
} 
While the causes of the abandonment of agricultural land and farming practices in LFAs are the same in most regions, the environmental impacts are spatially diverse. This means that they differ depending on both the type of abandonment and the characteristics of the environment. It follows that different CAP measures often transmit conflicting signals to farmers (McDonald et al. 2000; Haddaway et al. 2013).

In order to mitigate this risk and increase similarities with other areas, payment schemes were recognised $^{2}$ to apply to farmers located in LFAs based on the principle that the abandonment of agricultural practices occurs when the incomes they offer are not satisfactory and are lower than those perceivable for other activities or places (Strijker 2005; Partidário et al. 2009). The emerging trend from many studies (Strijker 2005; Partidário et al. 2009) is that the EU funds are not effectively implemented in LFAs and are mainly concentrated in the most productive agricultural areas. The European literature on the field of disadvantaged geographical areas frequently tends not to distinguish hill areas from mountain areas

Despite the margin of definition of different LFAs being very slight, in our work, for the peculiarity of the case study, we focus on distinguishing the criteria of high altitudes and slopes among mountain, hill and plain areas, aiming to verify whether the disadvantage (if any) is widening instead of helping to compensate for their natural handicaps.

Starting from these assumptions, and noting that agricultural systems are extremely complex and heterogeneous, our aim is to compare differences existing among different geographical areas (mountain, hill and plain) in a case study (Veneto Region, Italy) in terms of gross sellable product ${ }^{3}$ (GSP) per hectare of utilised agricultural area (UAA), as a proxy of land productivity. In addition, we explore the variables that affect it, with particular attention to the financial support of the first and second pillars of the CAP. In order to identify the factors influencing the variable GSP per hectare of UAA, we use descriptive statistics and a regression model. The year taken into account for our analysis is 2015 .

The study contributes to the literature by providing additional evidence on the existence of a productivity gap and a CAP funds allocation disparity among mountain, hill and plain farms in Veneto Region. Compared to previous approaches, in fact, our study presents the innovative aspect of taking into account every geographical area. The study also highlights the peculiar status of Veneto Region hill farms.

As a source of microdata, we use the Farm Accountancy Data Network (FADN). ${ }^{4}$ To define different geographical areas, we adopted the criteria utilised by the FADN based on the altitude of the farm's centre. ${ }^{5}$

The paper is organised as follows: in Sect. 2, we introduce the FADN database and the empirical methods used to develop our study. In Sect. 3, we present the case study. Finally, in Sect. 4 the main results achieved are reported and discussed. Some closing remarks will be highlighted in the conclusion.

\footnotetext{
2 The CAP recognises the payment scheme to compensate farmers for additional costs and loss of income resulting from natural constraints.

3 Indicator used in agricultural economics (Siciliano 2009).

4 A network developed at European level that collects accountancy data from farms for the determination of incomes and business analysis of agricultural holdings.

5 According to the FADN criteria, mountain farms are those placed above $600 \mathrm{~m}$ above sea level in the North of Italy (e.g. Veneto) and above $700 \mathrm{~m}$ in Southern and insular Italy. Hill farms are those located between 600 and $300 \mathrm{~m}$ above sea level, while plain farms are those that remain.
} 


\section{Materials and methods}

As a source of data, we consider the FADN, introduced in 1965 with Council Regulation (EEC) n. 79/65/EEC. Conducted annually, the FADN is committed to the collection of economic and structural data of a representative set of farms belonging to a defined field of observation. The field of observation is constructed by every farm holding operating in the agricultural sector with at least one ha of UAA or whose production has a value of at least $€ 2500 .^{6}$ Therefore, it excludes a further range of companies based on their economic dimension. Considering the different structures of agriculture in the EU, the limits of the economic dimensions of the EC's observation fields are different for each member state and are determined by specific regulations.

In Italy, where our case study is located, unlike the majority of the other member states, a random sampling procedure has been adopted since 2003. ${ }^{7}$ Participation in the survey is mandatory, but farmers receive different forms of incentive for their participation. In Italy, the incentive consists of the restitution to farmers of their accounting results or of the benchmark data. ${ }^{8}$

The Italian FADN sample is obtained through stratified random sampling, based on the information collected from the census archive, and takes into account three different variables, such as territorial collocation, economic dimension and technical economic orientation).

The FADN database has proved to be a valuable source of microdata (Longhitano 2012; Severini et al. 2016; Esposti 2017). The FADN procedure of stratification guarantees the representativeness of the sample; however, a representativeness limit is determined by its sampling method (Longhitano 2012; Esposti 2017).

The FADN sample, in fact, includes commercial farms that exceed a minimum threshold of agricultural production measured in European Size Units (ESU). This threshold varies among member states; in Italy, since 2014 it has been set at greater than 8 ESU (Esposti 2017). According to 2010 Istat census data, approximately $57.5 \%$ of Veneto farms had an economic size smaller than 8 ESU. It follows that also the FADN sample according to farm dimension is under-represented with respect to the whole universe of Veneto farms. ${ }^{9}$

In addition, the FADN also excludes the smallest farms with an UAA of less than 1 ha. It follows, on the one hand, that the category of small farms is under-represented and, on

\footnotetext{
6 Only forest-based companies do not fall within the EU's observation field.

7 For the selection of farms in the FADN sample, there are two main approaches:

The random selection from a list of farms derived from surveys on the structure of the farms.

The voluntary choice of companies, which always respects the selection plan.

${ }^{8}$ In other countries, farmers receive a cash payment equal to or less than the sum paid by the EU for the completion of the FADN business card.

${ }^{9}$ For instance, according to 2010 Istat census data, about $22.7 \%$ of Veneto farms had a dimension lower than 1 ha. In the FADN sample, instead those farms only represent 3.9\%. In addition, in our sample the percentages of farms with a UAA lower than 1 ha are divided as follows: $4.8 \%$ of mountain farms, $6.7 \%$ of hill farms and $3.3 \%$ of plain farms. These percentages show that the FADN sample underestimates the farms with a low dimension for every altitude class; in fact, according to the 2010 Istat census data $19.9 \%$ of Veneto Region mountain farms have a UAA lower than 1 ha, $28.5 \%$ of hill farms and $21.4 \%$ of plain farms. Although the FADN sample is unbalanced in terms of "number of farms per UAA", in terms of UAA the differences are much less pronounced. The percentage of UAA lower than 1 ha in the mountain is equal to 0.3 according to the 2010 Istat census, against $0.09 \%$ in our mountain sample. In the hill and plain, the percentages of UAA lower than 1 ha are $2.0 \%$ and $1.3 \%$, respectively (Istat census 2010), while in the FADN sample they are equal to $0.24 \%$ and $0.06 \%$, respectively.
} 
Table 1 Main structural characteristics of the farms of the sample by altitude (thousand of EUR) Source: Author's elaboration on FADN data, 2015

\begin{tabular}{llllll}
\hline Altitude & Farms & UAA & GSP & SP & Young farmer \\
\hline Classes & Number $(\%)$ & Mean (s.d.) & Mean per ha (s.d.) & Mean per ha (s.d.) & Number (\%) \\
Plain & $456(80.6)$ & $36.1(83.3)$ & $14.4(43.3)$ & $819.5(5933.4)$ & $31(6.8)$ \\
Hill & $89(15.7)$ & $16.2(35.5)$ & $24.8(144.7)$ & $1577.1(12,800.3)$ & $4(4.5)$ \\
Mountain & $21(3.7)$ & $48.0(58.9)$ & $5.8(9.2)$ & $312.9(5691)$ & $4(19.1)$ \\
Total & $566(100)$ & $33.4(77.2)$ & $15.7(69.0)$ & $919.9(7351.3)$ & $39(6.9)$ \\
\hline
\end{tabular}

$U A A$ utilised agricultural area, GSP gross sellable product, $S P$ standard production, $s . d$. standard deviation

the other, that the sample is composed of active and productive farms. This could be one explanation for the higher average value of UAA measured in our sample (33.3 hectares per farm, Table 1) compared with the census data of 2010 (6.7 hectares per farm). Therefore, the farms included in the FADN sample are by definition bigger and more productive than the average population, as participation in the FADN is a selective criterion itself.

Initially, we use descriptive statistics in order to highlight the allocation of the first and second pillar CAP funds among the sample's FADN Veneto farms divided by their altitude class. This allows us to verify whether the EU funding addresses problematic areas or existing healthy ones. Thereafter, we estimate a regression model in order to test whether there is a correlation between the GSP per ha of UAA, as a proxy of land productivity, and the altitude, as well as whether the EU funding influences such variables. The other controls we have taken into account in the analysis are those that, in our opinion, mainly affect the GSP. We refer, in particular, to the dimension of the farm (ha of UAA), the economic dimension (EUD) and the technical-economic orientation (TEO). Then we have included in the model other variables that have resulted being statistically significant such as whether the farmer is young or not and the legal form of the farm. In order to do so, we developed a regression model and estimated the regression equation through the ordinary least square (OLS) method. After defining the model's dependent variable, we restricted the sample of farms according to the following requirements:

- A GSP value per hectare of UAA between the 10th (more than 1642 euros per hectare of UAA) and the 90th (less than 22,282 euros per ha of UAA) percentiles of the overall distribution;

- Farms declaring to not carry out activities connected to agriculture, as they could alter the value of the effective GSP per ha.

The independent variables included in the model, in four subsequent specifications, are the following:

1. Dummies for the altitude ${ }^{10}$ (d_mountain and $\left.d \_h i l l\right)$ and a UAA index (Index_UAA) equal to the ratio between the farm's UAA and the average UAA of the altitude class to which they belong;

\footnotetext{
${ }_{10}$ We have excluded the dummy concerning the plain from the model in order to avoid the inconvenience of multicollinearity.
} 
2. EU financial support from the first pillar per geographical area $\left(F S \_E U_{-} I P \_\right.$plain, $F S_{-}$ $E U \_I P \_$mountain, $\left.F S \_E U \_I P \_h i l l\right)$;

3. EU financial support from the second pillar $\left(F S \_E U \_I I P \_p l a i n, F S \_E U \_I P \_\right.$mountain, $\left.F S \_E U \_I P \_h i l l\right)$;

4. Dummies for the technical-economic orientation ${ }^{11}$ (d_TEO_cultivations, $d \_T E O \_g r a n i-$ vores, $d \_T E O \_c u l t i v \_b r e e d i n g, d \_T E O \_h e r b i v o r e s, d \_T E O \_h o r t i c u l t u r e, d \_T E O \_p o l y-$ culture);

5. Dummy for whether the farm's owner is young (d_Young) and the variable concerning the legal form;

6. Dummies for the economic dimension ${ }^{12}\left(d \_E U D \_1, d \_E U D \_2, d \_E U D \_3, d \_E U D \_5\right)$.

\section{The case study}

Veneto is a region situated in Northeast Italy, with a population of approximately 4.9 million people (about $8 \%$ of the total Italian population) and a surface area of about $18,400 \mathrm{~km}^{2}$ (about $6 \%$ of the overall Italian territory). The land morphology has a lot of variety, from the Dolomites in the north (covering approximately $29 \%$ of the territory) to large areas of flat land in the south along the Po and Adige rivers (about 57\%), with some hill areas (14\%) both in the Alpine foothills and rising from the flat land. Veneto borders the Adriatic Sea to the east for more than $150 \mathrm{~km}$, along the Venice lagoon and the Po river delta. The climate is sub-continental, with different regimes in the Alpine region, and the hill and plain areas, and in the coastal area. Veneto is also home to many protected areas. According to the Natura 2000 network, 23\% of its territory is covered by 102 Sites of Community Interest (SCI) and 67 Special Conservation Zones (SCZ).

Even if its economy is based on SMEs (small and medium enterprises) spread throughout the territory, the region hosts internationally recognised clusters such as the eyewear industry and precision mechanics (Unionecamere Veneto 2016). However, SMEs with a high work intensity tend to be concentrated on the plain and coexist with a myriad of small farms. Although the economy of Veneto is based on industry and tourism, there is a notable tradition of agricultural production. The area covered by agriculture is larger than 800,000 ha ( $45 \%$ of the total regional surface) and is among the most productive in the country (Vanni and Povellato 2010). The last agricultural census identified 119,384 farms in Veneto (roughly $7.4 \%$ of the farms present in the Italian territory), with an average UAA of about 6.7 ha. Approximately $43 \%$ of the farms have a UAA lower than 2 ha, and on the other hand, the largest $4 \%$ of farms hold roughly $53 \%$ of the total regional UAA. Besides, more than $71 \%$ of the mountain farms are smaller than 5 hectares, in line with regional data.

\footnotetext{
11 We have excluded the dummy concerning cultivation breeding from the model to avoid multicollinearity and the one referring to polybreeding as this is not relevant for the number of farms involved.

12 The classes are the following (thousands of euro): [8;25), [25;50), [50;100), [100;500), [500;1000) and from 1000. The dummies are codified as follows: d_EUD_1 equal to 1 if the observation falls in the last 5 classes $(>=25,000)$, d_EUD_2 equal to 1 if the observation falls into the last 4 classes $(>=50,000), d_{-}$ EUD_3 equal to 1 if the observation falls into the last 3 classes $(>=100,000)$, d_EUD_4 equal to 1 if the observation falls into the last 2 classes $(>=500,000)$ and d_EUD_5 equal to 1 if the observation falls into the last class $(>=1000,000)$.
} 
Most of these farms are located in the fertile plain areas $(76.7 \%)$, where the production consists of cereals (maize and wheat), soybean and horticulture cultivations. A sizeable cluster of farms is located in the hill areas (18.7\%) and is devoted to the production of grapes for well-known wines, such as Amarone, Bardolino, Valpolicella and Prosecco. The coastal areas are instead dedicated to the long tradition of shellfish farms. Only $4.6 \%$ of the farms are located in the mountains, the majority of which are devoted to zootechnical and forest activities; $64.4 \%$ of the mountain areas are covered by grasslands and pastures, while the regional agricultural area is predominantly destined for arable and crops.

In contrast to the trends of previous decades, in recent years Italy's population growth has seemed to be slowing, which is reflected in the Veneto Region (a decrease of $0.41 \%$, about 20,067 individuals, from 2015 to 2017). In fact, since 2015, the number of permanent Italian residents in Veneto has dropped for the first time in 60 years. The most affected areas are those located in the mountains.

According to the report from Montagna Veneta 2020 (2013), the depopulation issue involves 53 out of 63 wholly mountainous municipalities in the province of Belluno, ${ }^{13}$ 18 of the 37 municipalities in the province of Vicenza, 7 of the 18 wholly mountainous municipalities in the province of Verona and 3 of the 11 municipalities in the province of Treviso. In particular, according to Istat data, the population of permanent residents in the mountains of Belluno Province was decreased by $1.03 \%$ (about 1075 individuals) between 2015 and 2017. In addition, an internal migratory movement has been detected within the mountain areas, favouring partially mountain municipalities located further downstream and discriminating against elevated or remote municipalities.

Veneto mountain areas also register worsening demographic indicators with respect to the average regional ones. In 2010, the birth rate was $8.9 \%$ (9.5\% in Veneto), while the mortality rate was equal to $10.7 \%$ (9.1\% in Veneto), demonstrating a lower natural growth rate (Istat 2011).

The breakdown of the evolution of Veneto population by age confirms the progressive change in the structure of its population, which is increasingly concentrated in the highest age groups. However, in Veneto mountain areas, the share of elderly people is above the regional average, while the share of young people is below it. It follows a higher dependency ratio, as well as a higher old-age index (Montagna Veneta 2020 2013).

In our study, the sample consists of 566 farms. Despite the peculiarity of the FADN field of observation, the distribution of the farms in the sample is very close to the census distribution of Veneto farms with respect to the altitude classes. More than $80 \%$ are located on the plain, about $16 \%$ in the hills and a scarce $4 \%$ in the mountains.

Half of the plain farms in the sample specialise either in arable $(32 \%)$ or in cultivations (18\%) and about a third in breeding. Almost $75 \%$ of the plain farms cultivate crops (both individually and alongside other cultivations), and more than $50 \%$ deal with industrial cultivations. More than a quarter produce wine. Farms specialising in cultivations are definitely more frequent in the hills (52.8\%). Less frequent, about 20\%, are those specialising in breeding. Viticulture is the most common cultivation of the hill farms; in fact, about $62 \%$ own a vineyard. Crops (about $45 \%$ ), meadows and pastures (almost $43 \%$ ) follow viticulture.

All the mountain farms are specialised in the breeding either granivores or herbivores. Therefore, the main activity is forage cultivation (grasslands, meadows and pastures), but

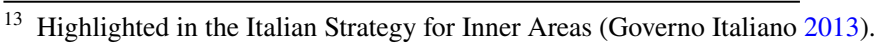


the cultivation of crops (38\%) and viticulture (14\%) are present as well. About a quarter have multifunctional activities such as the production of solar energy and environmental services of farmhouses (hospitality, restaurants and the tasting of products).

What emerges from Table 1 is that, on average, mountain farms tend to be the largest (on average $48 \mathrm{ha}$ ) and hill farms the smallest (on average $16 \mathrm{ha}$ ). The larger UAA is especially due to the presence of meadows and pastures for extensive breeding. Meadows and pastures, in fact, relate to livestock holdings, and not to agricultural holdings.

The UAA per cent distributions of the population are quite similar to those of plain farms according to the last Istat agricultural census of 2010, where an UAA not exceeding 20 ha characterises more than half of the farms. Regarding hill farms, we have detected a great predominance of small farms (almost 40\%) with an UAA lower than 5 ha. The percentage of mountain farms, on the other hand, shows a peak (almost 30\%) in the UAA class between 50 and 100 ha, while small farms make up approximately 10\%. It is, however, necessary to note that the number of farms located in the mountain is very low if compared to the total sample, and for this reason, singularities have a greater weight. Furthermore, 25\% of the total sample has a UAA lower than 6 ha, while the median value is 13.9 has, less than half of the average UAA of the sample.

Plain farms have, on average, the highest level of $\mathrm{GSP}^{14}$ (307.2 thousand euros), followed by mountain farms (287.7 thousand euros) and hill farms (156.3 thousand euros). However, as shown in Table 1, when looking at the average GSP per ha, the roles reverse. As a matter of fact, the average GSP per ha is the lowest in the mountains (5.8 thousand euros per ha), while in the hills it is the highest (24.8 thousand euros per ha). This result is consistent with the different farm size, in terms of UAA, previously detected when considering the different altitudes. The same rank emerges for the standard production (SP) values: mountain farms record the lowest average level of SP per ha equal to 313 thousand euros per ha. While the GSP includes the EU funds of the first pillar, the SP includes neither the EU funds of the first pillar nor those of the second.

Table 1 shows the distribution of "young farmers" by altitude. This variable is important because young farmers are able to receive additional support from the CAP. In our sample, farmers who do not belong to the "young farmers" category own the great majority of farms (almost 93\%). What emerges is that for both plain and hill farms, the percentage of young farmers is below the sample percentage of $6.9 \%$, while for mountain farms this percentage is definitely higher (19.1\%, corresponding to 4 people over 21 in total).

For the EUD, ${ }^{15}$ almost $80 \%$ of farms have an overall economic dimension between 8000 and 500,000 euros, and the most crowded class is from 100,000 to 500,000 euros (about $31 \%$ ). Looking at the EUD per ha, the sample becomes more homogeneous; in fact, more than $80 \%$ of the farms fall into the first class (between 8000 and 25,000 euros).

In our sample, the prevalent $\mathrm{TEO}^{16}$ changes consistently according to the altitude (Table 2). On the plains, almost a third of farms (32\%) are specialised in arable production, while almost a fifth (18.6\%) are specialised in cultivations. Breeding is less frequent; in

\footnotetext{
14 The GSP is defined by the FADN as, "the value of agricultural production obtained from the sale, both primary and processed products, self-consumption, gifts, in-kind wages, capitalization of cost for buildings and extraordinary maintenance, from the recovery animal welfare and public subsidies from the first pillar of the CAP".

15 The EUD is the amount in euros of the farm's standard production. The SP of FADN farms is instead measured as, "the monetary value of plant or animal production, including sales, re-utilization, self-consumption and the change in product stock".

16 The TEO is the percentage of the SP of farms' production activities compared to their own total SP.
} 


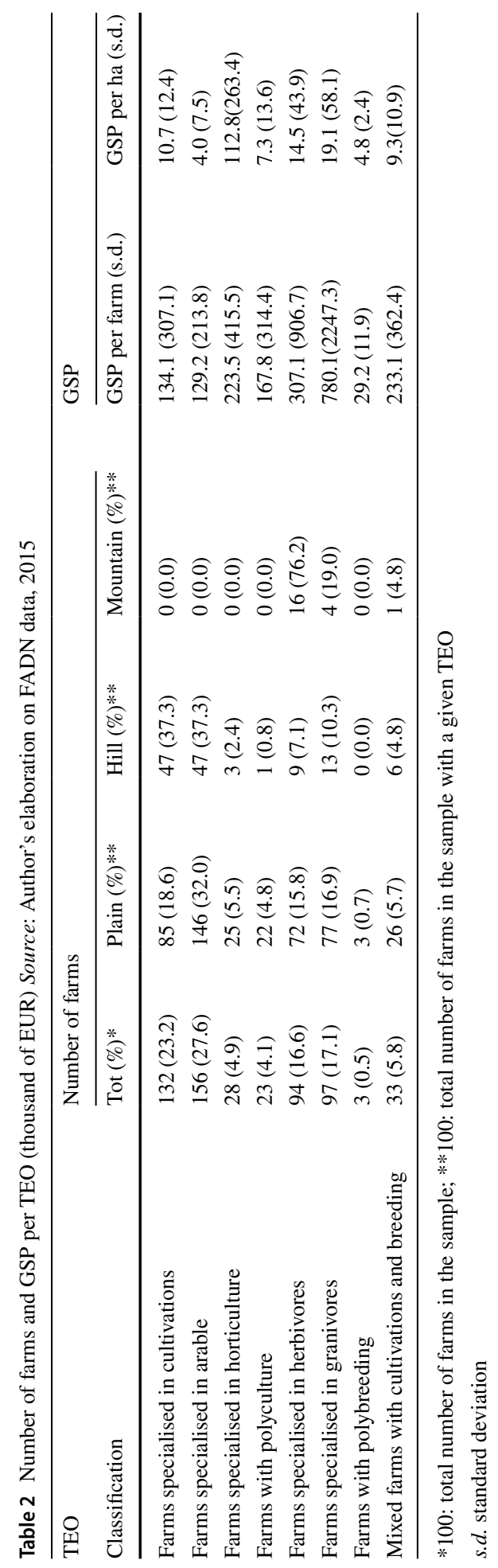


fact, about $30 \%$ of farms are specialised in either herbivores $(15.8 \%)$ or granivores $(16.9 \%)$. When looking at hill farms, the percentage specialised in agriculture is higher $(52.8 \%$ in cultivations and $11.2 \%$ in arable production), while that of farms specialised in breeding is lower ( $10.1 \%$ in herbivores and $14.6 \%$ in granivores). Mountain farms are instead all specialised in breeding: $76.2 \%$ in herbivores and $19.0 \%$ in granivores; the remaining $4.8 \%$ consists of farms specialising in both cultivations and breeding (Table 2).

As shown in Table 2, the highest average values of GSP per ha are, once again, associated with the categories of farms specialised in granivores (780.1 thousand euros) and herbivores (307.1 thousand euros). The trend repeats even when taking into account the GSP per ha of UAA, with the exception represented by those farms specialising in horticulture. The latter shows a very high GSP value over the UAA due to the restricted UAA (usually under 5 ha).

\section{Results and discussion}

Aiming to verify the allocation of the CAP funds, Table 3 reports the number of farms in the sample (total and divided by altitude) receiving financial support from the first and second pillars in 2015. Table 4 focuses on the former second axis of the second pillar, which was related to the environment. ${ }^{17}$

Almost all of the sample (87\%) receives funds from the first pillar, 32\% receives funds from the second pillar and $31 \%$ receives both. A plain farm, on average, receives 32.2 thousand euros from the first pillar, while a mountain farm receives only half of this. On the other hand, on average, a mountain farm receives a higher amount (about 37.2 thousand euros per farm) from the second pillar than plain and hill farms, coherently with Cagliero and Henke (2006). Almost 80\% (17 out of 21) of the mountain farms received financial support from the second pillar; a net difference exists if taking into account plain and hill farms ( $31 \%$ and $28 \%$, respectively).

Moreover, all the mountain farms have received financial support from both the first and the second pillars. Regarding plain and hill farms, about a third of those receiving funding from the first pillar have also received funding from the second pillar.

Although the 2003 CAP reform has largely removed artificial incentives to intensify production, the many challenges agriculture management in less favoured areas has to face, in order to limit progressive depopulation, biodiversity loss and environmental degradation, continue to be disregarded. Analysing the redistributive effects of the direct payment introduced in 2013, Ciliberti and Frascarelli (2018) underlined that, if the public resources devoted to the voluntary couple support had been destined to the redistributive payments or for mountains area payments, a more equitable distribution of resources would have been achieved.

Our empirical analysis provides additional evidence for this trend: $81.5 \%$ (14.1 million out of 17.3 million euros) of the total EU funds directed to the farms in the sample are absorbed by the first pillar, of which about $94 \%$ (13.2 million euros) have been directed to plain farms (mainly producing arable crops). Likewise in Cagliero and Henke's study

\footnotetext{
17 The Veneto Rural Development Plan (RDP) for the 2014-2020 period has identified two environmental priorities: Priority 4-preserving, restoring and enhancing ecosystems - and Priority 5-promoting the efficient use of resources and the transition to a low-carbon economy. These environmental Priorities have over 398 million euros available, equal to $33.7 \%$ of the total financial resources (Regione Veneto 2015).
} 


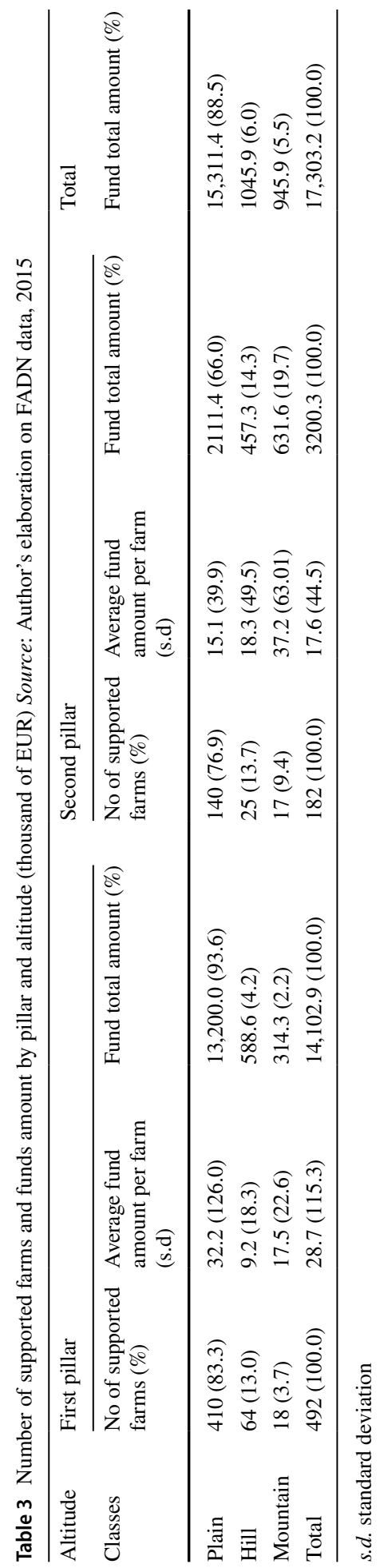


Table 4 Number of supported farms and funds amount former Axis 2 environment by altitude (thousand of EUR) Source: Author's elaboration on FADN data, 2015

\begin{tabular}{|c|c|c|c|}
\hline \multirow{2}{*}{$\begin{array}{l}\text { Altitude } \\
\text { Classes }\end{array}$} & \multicolumn{3}{|c|}{ Second pillar-Axis 2 environment } \\
\hline & $\begin{array}{l}\text { No of sup- } \\
\text { ported farms } \\
(\%)\end{array}$ & $\begin{array}{l}\text { Average fund } \\
\text { amount per farm } \\
\text { (s.d) }\end{array}$ & Fund total amount (\%) \\
\hline Plain & $38(71.7)$ & $9.1(13.0)$ & $344.8(84.3)$ \\
\hline Hill & $8(15.1)$ & $2.7(1.8)$ & $21.5(5.3)$ \\
\hline Mountain & $7(13.2)$ & $6.0(3.9)$ & $42.3(10.4)$ \\
\hline Total & $53(100.0)$ & $7.7(11.4)$ & $408.6(100.0)$ \\
\hline
\end{tabular}

s.d. standard deviation

(2006) where, using the FADN database at Italian level, the CAP support has still be found highly concentrated in the first pillar, especially among farms specialised in crops. Therefore, $18.5 \%$ of the second pillar remains, of which the majority, $66 \%$, goes to plain farms (2.1 million out of 3.2 million euros).

It follows that $88.5 \%$ of the total EU funds (more than 15.3 million euros) goes to plain farms, while 6\% (1.0 million) and 5.5\% (945 thousand) are left to hill farms and mountain farms, respectively.

In our sample, the former Axis $2^{18}$ (Table 4) absorbs only $12.7 \%$ of the second pillar, for a total of 408.6 thousand euros, and only $2.4 \%$ of the total EU funds. Moreover, in this case the greatest part goes to plain farms (84.3\%); nevertheless, mountain farms receive more funding than hill farms.

After demonstrating the EU financial support framework within the sample, the hypothesis we intended to verify is whether a correlation exists between the Veneto mountain farms of the sample and those located in the plains and hills in terms of GSP per ha of UAA (our dependent variable).

The results of the regressions (Table 5) confirm our hypothesis about the existence of a correlation for the GSP per ha of UAA between mountain and plain farms in the Veneto Region. In all specifications, in fact, the coefficient of the dummy variable for the mountain farms ${ }^{19}$ is negative and highly significant at the 0.01 level. In particular, in the last specification, after all controls were added, the average value of a farm's GSP per ha was lower than 5815 euros per ha if the farm was in a mountain area. On the other hand, hill farms, on average, possessed a higher GSP per ha of UAA of 969.5 euros when compared to plain farms; however, the coefficient is not statistically significant.

The coefficient of the UAA index variable is negative and highly significant ( 0.01 level). This implies that, taking into account the altitude, for each extra ha the GSP per ha is lower by 780 euros.

Some of the significant coefficients of the dummy variables related to the TEO are positive, while others are negative. In particular, and concerning breeding, farms specialised in herbivores record, on average, a value per ha of a GSP higher by 2190 euros, while the value per ha of those specialising in granivores is lower by 2567 euros, when compared with farms specialised in both cultivation and breeding.

The dummy variable indicating whether the farm's owner is young also presents a positive coefficient, which is statistically significant at the 0.05 level. This can be

\footnotetext{
18 The amounts refer to the multiannual financial commitments of the programming period 2007-2013.

19 Equal to 1 if the farm is located in a mountain area, 0 otherwise.
} 


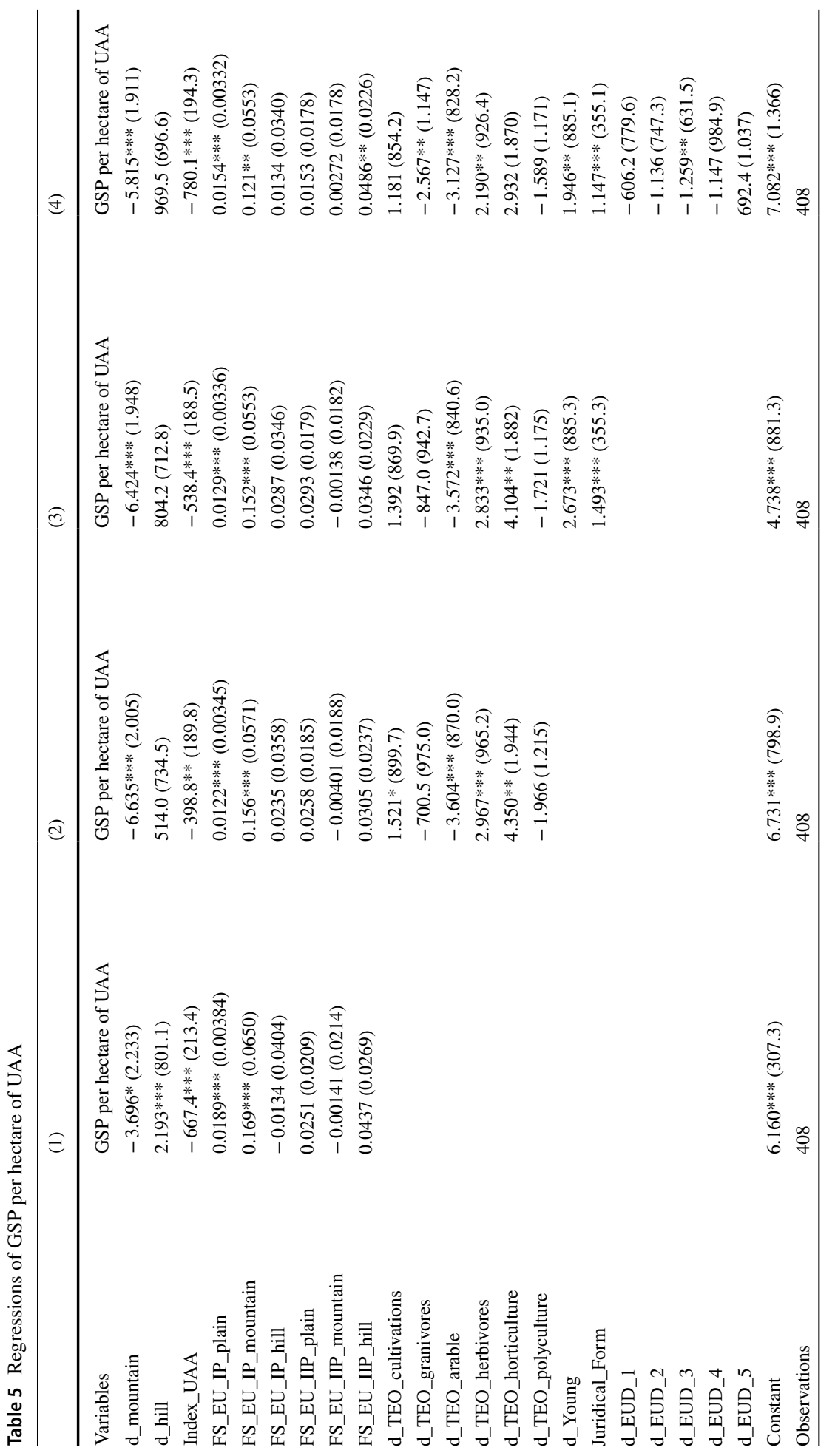




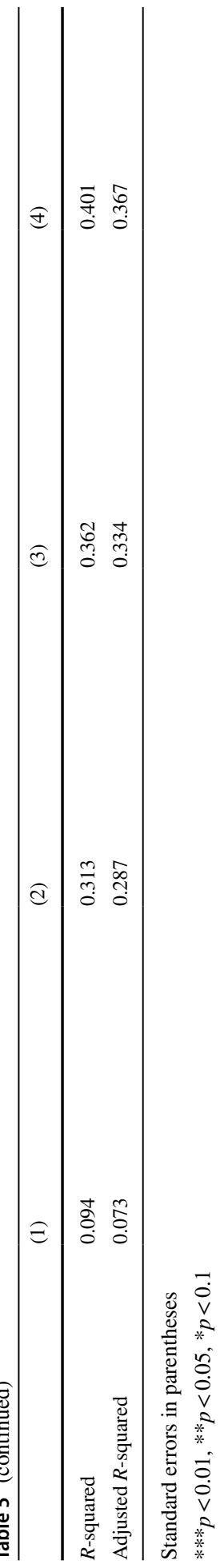

型 Springer 
interpreted by the fact that farms managed by young people record a GSP of higher than 1946 euros per ha, on average.

As highlighted in the paper of Rizov et al. (2013), investigating the impact of the CAP financial support on farm productivity using the FADN samples for the EU15 countries, after decoupling in 2003, subsidies positively affect productivity in several EU countries analysed. However, there is also a consistent part of the literature stating the negative relationship between CAP subsidies (especially coupled) and various measures of productivity (Zhu et al. 2012; Rizov et al. 2013).

In our analysis, a positive correlation between EU payments of the first pillar and GSP per hectare of UAA is detected.

In addition, by looking at the altitude differentiation, the coefficients of the variables expressing the EU financial support of the CAP's first pillar are positive and statistically significant for both plain and mountain farms. According to this result, this financial support is positively correlated with GSP per ha and, on average, for mountain farms is related to an increase of $12.1 \%$ of the dependent variable.

These results confirm what emerged in the study of Brady et al. (2017): the magnitude of impacts of EU payments of the first pillar varies across different altitude regions due to spatial variability in productivity. Mountain farms with large areas of less productive land are more influenced by direct payments than more productive plain farms, because this land would be farmed in any case. Hill farms, with the highest value of GSP per hectare UAA in our case, are instead not influenced at all by the payments of the first pillar.

For what concerns the second pillar of the CAP, the prevalent literature has found it to have no significant impact on farm productivity. This outcome is obtained, for instance, in the study of Dudu and Smeets Kristkova (2017), aiming at estimating the impact of CAP second pillar payments on agricultural productivity for EU countries over the period 2007-2013. The result achieved, moreover, does not change among member states depending on the date of access to the European Union, spatial characteristics or size of the countries. A similar conclusion is drawn in Mary's study (Mary 2013) which takes into account a FADN dataset of French farms between 1996 and 2003.

In line with the results of the aforementioned studies, the coefficient of the EU funds of the second pillar is not significant in all specifications for both plain and mountain farms. This implies that the financial support does not help in reducing the GSP per ha gap between mountain and plain farms. In addition, the analysis of residuals provides evidence that there is no correlation between these findings and the residues, and therefore, they do not contribute to explaining the model.

The differentiation among altitude classes, however, has highlighted that the coefficient results are positive and statistically significant in the last specification related to hill farms $(+4.9 \%)$.

To summarise, what emerges from the regression is that the GSP per hectare is negatively influenced by farm location in the mountains and positively influenced by the CAP payments of the first pillar, although not for hill farms. The payments of the second pillar, on the other hand, do not seem to affect the dependent variable, with the only exception of hill farms. The latter, in fact, although designed to support a balanced territorial development of rural economies, is scarce and mainly addressed to hill and plain farms.

Despite the presence of specific measures and actions dedicated to rural development, the difference in the level of aid received appears increasingly difficult to justify, especially when looking at the reforms that should support multifunctionality and environmental protection. 
From the first specification, and including the altitude dummies, the UAA and the CAP funding to the first and second pillars, including the TEO dummy, the age of the farm owner, the economic dimension and the farm's legal form, the R-squared is raised from 0.09 to 0.40 . Therefore, the model is able to explain more than a third of the variability.

One problem concerns the lack of relevance of the OLS method. In fact, the estimation of the regression equation is not consistent in the case of the mountainous dummy, conditional on the other explanatory variables, and is correlated with the error term. In this case, therefore, we cannot talk about a causal effect of the altitude on GSP per hectare of UAA, but in relation to the correlation. This issue may occur when unobserved farms' characteristics are correlated with the altitude and, due to their potential omission, can lead to biases of the effect of the altitude on the GSP per hectare. The sign of this distortion depends on the correlation between the mountain dummy and the unobserved variable, and the impact of the latter on the proxy of land productivity. The different levels of difficulty in carrying out the same farm activity because of different altitudes are an example of this.

\section{Conclusions}

In line with Ciliberti and Frascarelli (2018), our empirical analysis provides additional evidence for the necessity of a more equitable distribution of CAP resources; in fact, it shows that a large majority of CAP funds in Veneto are channelled into the first pillar (almost $81.5 \%-14.1$ million euros in our sample) and is, therefore, mainly addressed to plain farms (88.5\% - 13.2 million euros) and only partially addressed to mountain farms $(2.2 \%-314$ thousand euros). Being scarce, the financial support to the second pillar is not able to effectively mitigate the gap: about $18.5 \%$ of EU funds- 3.2 million of euro-are directed to the second pillar in our sample (and only $2.4 \%$ of them to former Axis 2 Environment). Mountain farms have received only $19.7 \%$ of those funds, equal to 631.6 thousand euros, against the $66 \%$ of plain farms -2.1 million euros. This results in an increased gap between disadvantaged rural areas, such as mountains, and more favoured areas. The regression analysis shows that the GSP per ha of UAA is negatively correlated with the location of the farm in the mountains, while the hill location is not statistically significant. This result confirms the existence of a gap in terms GSP per hectare of UAA between mountain and plain farms. The dependent variable is, moreover, positively influenced by the financial support of the first pillar, for all farm locations with the exception of hills. The CAP payments of the second pillar, on the other hand, are positively correlated only with the GSP per hectare of UAA of hill farms (which have the average highest level of GSP per hectare of UAA). These results confirm the scarce efficiency, in economic terms, of the initiatives promoted by the second pillar, as the latter are aimed to support a balanced territorial development of rural economies. It follows that, in line with the study ${ }^{20}$ of Hinojosa et al. (2016), EU support policies for maintaining agricultural activity in marginal areas are not fully effective in reducing the abandonment of mountain lands.

According to our opinion, the CAP policies should be reviewed and redesigned, outlining the importance of a more equitable redistribution of funds, better linked to the provision of public goods, in order to ensure the protection of the environment; the loss of the rural population carries with it environmental degradation. Considering the complex heterogeneity of the agricultural systems and of rural areas, a bottom-up approach is required.

\footnotetext{
20 The study focuses on the causes of abandonment of grasslands from 1990 to 2006 in the French Southern Alps.
} 
The unfavourable areas need to be supported with tailored policies in order to avoid their irreversible degradation.

In our case study, an unusual result comes from the analysis of the farms located in hill areas. Hill farms are performing better not only than mountain farms but also than plain farms. Viticulture, in fact, is the main business in the area, producing high-quality, globally recognised wines, showing that farms with territorial disadvantages can find their own way to efficiency and the remuneration of production factors regardless of European support. Naturally, this study cannot be extended to all European hill areas. It confirms, however, how different not only mountain areas, but also hill areas can be. Other similar and further studies could be conducted in different European regions to highlight the effects of the choices made by other European countries, for instance in the definition of homogeneous areas, using less traditional methods than Italian ones.

Lastly, a few comments on the European Commission proposals for the post-2020 CAP, presented in 2018 (European Commission 2018) and addressed to the fight against climate change, to the generational turnover and to the support of European farmers for sustainable and competitive agriculture. ${ }^{21}$

The planned funding is slightly lower than previous funding, and the structure of the interventions does not seem substantially modified. In our opinion, this proposal seems strongly influenced by domestic and external concerns and, among them, those deriving from the world stagnation process, from growing protectionist practices and from the expected Brexit impacts, rather than a real conviction to support farms located in areas with natural handicaps better than in the past.

In actual fact, for areas with natural handicaps (or areas with natural constraints), the available documents seem to invite sustainable, but integrated, development paths which should be matched by structural funds, almost a return to the first edition of the structural funds reform (European Commission 2019). This could be a choice: abandonment and/ or degradation is not resolved by strengthening or privileging only the primary sector, but they require interventions in the field of infrastructure (improving sustainable accessibility), job opportunities (not necessarily restricted to the agricultural sector), investments in human resources and the environment, combining top-down and bottom-up approaches. In our case study, the interventions of the second pillar combined with the distribution of the resources of the first pillar have demonstrated the inability to bridge the natural territorial differences.

\section{References}

Agnoletti, M. (2007). The degradation of traditional landscape in a mountain area of Tuscany during the 19th and 20th centuries: Implications for biodiversity and sustainable management. Forest Ecology and Management, 249(1-2), 5-17. https://doi.org/10.1016/j.foreco.2007.05.032.

Brady, M., Hristov, J., Höjgård, S., Jansson, T., Johansson, H., Larsson, C., Nordin, I., Rabinowicz, E. (2017). Impacts of direct payments-lessons for CAP post-2020 from a quantitative analysis. AgriFood Economics Centre no. 2017: 2.

Cagliero, R., Henke, R. (2006). Evidence of CAP support in Italy. Between first and second pillar [Common Agricultural Policy]. PAGRI-Politica Agricola Internazionale (Italy).

21 Among the nine objectives of the future CAP, the environmental ones are: contributing to climate change mitigation and adaptation, as well as sustainable energy; fostering sustainable development and efficient management of natural resources such as water, soil and air; and contributing to the protection of biodiversity, enhanced ecosystem services and preservation of our habitats and landscapes (European Commission 2019). 
Ciliberti, S., \& Frascarelli, A. (2018). The CAP 2013 reform of direct payments: Redistributive effects and impacts on farm income concentration in Italy. Agricultural and Food Economics, 6, 19.

Council of the Economic Community. (1965). Council Regulation No. 79/65/EEC of the 15 June 1965 setting up a network for the collection of accountancy data on the incomes and business operation of agricultural holdings in the European Economic Community. Official Journal 1859/65. https://eurlex.europa.eu/legal-content/EN/TXT/PDF/?uri=CELEX:31965R0079\&from=EN. Accessed 19 Mar 2018.

Council of the Economic Community. (1975). Council Directive No. 75/268/EEC of the 28 April 1975 concerning mountain and hill farming and farming in certain less- favoured areas. Official Journal L128/1. https://eur-lex.europa.eu/legal-content/EN/TXT/PDF/?uri=CELEX:31975L0268\&from=IT. Accessed 21 Mar 2018.

Defrancesco, E., Gatto, P., \& Mozzato, D. (2018). To leave or not to leave? Understanding determinants of farmers' choices to remain in or abandon agri-environment schemes. Land Use Policy, 76, 460-470.

Dudu, H., Smeets Kristkova, Z. (2017). Impact of CAP Pillar II payments on agricultural productivity. EUR 28589 EN, Publications Office of the European Union, Luxembourg, 2017, ISBN 978-92-79-68723-5, JRC106591, https://doi.org/10.2760/802100.

Esposti, R. (2017). The heterogeneous farm-level impact of the 2005 CAP-first pillar reform: A multivalued treatment effect estimation. Agricultural Economics, 48(3), 373-386.

European Commission. (2018). Future of the common agricultural policy, legislative proposal. https:// ec.europa.eu/info/food-farming-fisheries/key-policies/common-agricultural-policy/future-cap_en. Accessed 10 Sept 2018.

European Commission. (2019). The environmental objectives of the future CAP. https://ec.europa.eu/info/ news/environmental-care-and-climate-change-objectives-future-cap-2019-jan-25_en. Accessed 4 Apr 2019.

European Union. (1957). Treaty establishing the European community (Consolidated Version), Rome Treaty. https://ec.europa.eu/romania/sites/romania/files/tratatul_de_la_roma.pdf. Accessed 10 Mar 2018.

Governo Italiano-Agenzia per la Coesione Territoriale. (2013). Accordo di Partenariato 2014-2020, Strategia Nazionale per le Aree Interne. http://community-pon.dps.gov.it/areeinterne/progetto-areeinterne/la-strategia-nazionale-per-le-aree-interne/. Accessed 16 Apr 2019.

Haddaway, N. R., Styles, D., \& Pullin, A. S. (2013). Environmental impacts of farm land abandonment in high altitude mountain regions: A systematic map of the evidence. Environmental, 2, 18.

Hinojosa, L., Napoléone, C., Moulery, M., \& Lambin, E. F. (2016). The "mountain effect" in the abandonment of grasslands: Insights from the French Southern Alps. Agriculture, Ecosystems \& Environment, $221,115-124$.

Istat. (2010). Data on the agriculture census of 2010 in Veneto. http://www4.istat.it/en/veneto/data. Accessed 15 Nov 2019.

Istat. (2011). Data on Veneto demography. http://demo.istat.it. Accessed 5 Apr 2018.

Longhitano, D., Bodini A., Povellato A., Scardera A. (2012). Use of FADN for monitoring farm sustainability: Strengths and weaknesses of current database. In: Vrolijk H. (Ed.), Pacioli 19, The role of FADN after the CAP reform, LEI Memorandum 12-014, Wageningen.

Mary, S. (2013). Assessing the impacts of pillar 1 and 2 subsidies on TFP in French crop farms. Journal of Agricultural Economics, 64(1), 133-144.

McDonald, D., Crabtree, J. R., Wiesinger, G., Dax, T., Stamou, N., Fleury P., Gutierrez Lazpita, J., \& Gibon, A. (2000). Agricultural abandonment in mountain areas of Europe: Environmental consequences and policy response. Journal of Environmental Management. https://doi.org/10.1006/jema.1999.0335. http://www.idealibrary.com. Accessed 10 May 2018.

Montagna Veneta 2020. (2013). Un patto per la crescita intelligente, sostenibile e inclusiva delle zone montane del Veneto. Position Paper dei Rappresentanti delle zone montane del Veneto sulla preparazione dei Programmi operativi e del Programma di sviluppo rurale del Veneto per il periodo 2014-2020 - 11 dicembre 2013. https://www.montagneinrete.it/uploads/tx_gorillary/montagna_veneta_2020_final e_12_12_20131_1516011941.pdf. Accessed 29 Mar 2019.

Partidário, M. R., Sheate, W. R., Bina, O., Byron, H., \& Augusto, B. (2009). Sustainability assessment for agriculture scenarios in Europe's mountain areas: Lessons from six study areas. Environmental Management. https://student.cc.uoc.gr/uploadFiles/181\%CE\%91\%CE\%93\%CE\%A1\%CE\%9A390/susta inability\%20assessment\%20of\%20mountain\%20EU\%20areas.pdf. Accessed 15 Apr 2019.

Regione Veneto. (2015). Guida al PSR Veneto 2014-2020. Veneto Agricoltura Azienda Regionale per i Settori Agricolo Forestale e Agroalimentare. http://www.consiglioveneto.it/crvportal/upload_crv/servi ziostudi/1458826155577_Guida_al_PSR_2014_2020.pdf. Accessed 22 Apr 2019. 
Rizov, M., Pokrivcak, J., \& Ciaian, P. (2013). CAP subsidies and productivity of the EU farms. Journal of Agricultural Economics, 64(3), 537-557.

Severini, S., Tantari, A., \& Di Tommaso, G. (2016). Do CAP direct payments stabilise farm income? Empirical evidences from a constant sample of Italian farms. Agricultural and Food Economics, 4, 6.

Siciliano, G. (2009). Social multicriteria evaluation of farming practices in the presence of soil degradation. A case study in Southern Tuscany, Italy. Environment, Development and Sustainability. https://doi. org/10.1007/s10668-008-9169-9.

Strijker, D. (2005). Marginal lands in Europe_causes of decline. Basic and Applied Ecology, 6(2), 99-106. https://doi.org/10.1016/j.baae.2005.01.001.

Unionecamere Veneto. (2016). La situazione economica del Veneto. Rapporto annuale 2016. Unioncamere del Veneto-Area Studi e Ricerche, Venezia (2016). ISBN 978-88-902310-5-6. http://rapportoannuale .unioncamereveneto.it/wpcontent/uploads/manual/pdf/Rapporto\%20Annuale\%202016\%20-\%20La\%20 situazione\%20economica\%20de1\%20Veneto.pdf. Accessed 20 Sept 2018.

Vanni, F., Povellato, A. (2010). Delivering public goods through agriculture. Some evidence from viticulture in Veneto region. In Proceedings of the international conference "Enometrics XVII". Palermo June 9-12, 2010.

Verburg, P. H., \& Overmars, K. P. (2009). Combining top-down and bottom-up dynamics in land use modelling: Exploring the future of abandoned farmlands in Europe with the Dyna-CLUE model. Landscape. https://doi.org/10.1007/s10980-009-9355-7.

Westhoek, H. J., Van den Berg, M., \& Bakkes, J. A. (2006). Scenario development to explore the future of Europe's rural areas. Agriculture, Ecosystems \& Environment, 114(1), 7-20.

Zhu, X., Milán Demeter, R., \& Lansink, A. O. (2012). Technical efficiency and productivity differentials of dairy farms in three EU countries: The role of CAP subsidies. Agricultural Economics Review, 13(3892016-23490), 66-92.

Zolin, M. B., Ferretti, P., \& Némedi, K. (2017). Multi-criteria decision approach and sustainable territorial subsystems: An Italian rural and mountain area case study. Land Use Policy, 69, 598-607.

Publisher's Note Springer Nature remains neutral with regard to jurisdictional claims in published maps and institutional affiliations. 